\title{
Constructing Emergency Logistics Technology System Based on System Requirement Engineering
}

\author{
Dong $\mathrm{Xu}^{1, \mathrm{a}}$, Chuan Wang ${ }^{2, \mathrm{~b}}$ and Lei Zhang ${ }^{1, \mathrm{c}}$ \\ ${ }^{1}$ National Defense University Joint Logistics College, Beijing, China; \\ ${ }^{2}$ Beijing Jiaotong University, Beijing, China. \\ a13331092806@126.com, b17120592@bjtu.edu.cn, czhanglei@lsec.cc.ac.cn
}

Keywords: Emergency logistics, Technical system, System engineering, System requirements.

\begin{abstract}
The construction of emergency logistics technology system answers the question of where the emergency logistics technology system comes from. Based on the principles of system engineering and system requirements engineering, this paper compares existing achievements in constructing emergency logistics technology system, and analyzes the characteristics of capability requirement, equipment requirement and emergency logistics technology in emergency logistics system. This paper puts forward the construction method of emergency logistics technology system, and establishes emergency logistics technology system based on emergency logistics flow.
\end{abstract}

\section{Introduction}

Emergency logistics technology is an important foundation for the construction of emergency logistics system, and it is an important driving force to promote the development of emergency logistics. The demand for emergency logistics is becoming more and more urgent for emergency logistics technology. At the same time, along with the rapid development of science and technology, information technology, control technology, management science and modern science and technology has penetrated into all aspects of emergency logistics activities, to put forward higher requirements for the development of emergency logistics system of emergency logistics activities needed for emergency logistics technology. Research of emergency logistics system construction, to adapt to the current requirements and tasks and adapt to technological development characteristics and reasonable structure of emergency logistics system, to promote the development of emergency logistics technology, improve the service ability of emergency logistics system, to adapt to the needs of emergency logistics activities, is of great significance.

\section{Research Status and Relative Concepts}

\subsection{Relative Concepts.}

The emergency logistics technology system refers to a set of technologies that consist of various technologies, including hierarchical structure and system characteristics, to meet diversified, multi-level capabilities and equipment needs. The core of the emergency logistics technology system is the relationship between technology and technology. All technologies come from the current or future capabilities and equipment needs of the emergency logistics system. The relationship between technologies stems from the relationship between technology and capability demand and equipment demand, partly from the attributes of technology itself, such as level, category and so on. This clarifies the source of the emergency logistics technology system: the capability demand and equipment demand driven by specific or unspecific emergency logistics support tasks. At the same time, this also explains the fundamental purpose of the construction of the emergency logistics technology system, to meet the current or future capacity requirements and equipment requirements of the emergency logistics system.

The emergency logistics technology system has the following characteristics: 
All the technologies in the emergency logistics technology system are essentially homogeneous. Technology has common basic attributes, such as technology maturity, level, and category and so on. This is essentially different from the emergency logistics activities in the emergency logistics system. All kinds of emergency logistics activities have their own technical requirements, and the technical indicators of different types of equipment may be completely different. In addition, there are various elements in the emergency logistics system, such as guarantee task, guarantee activity, ability, function, equipment and so on. Therefore, the elements of the emergency logistics technology system are essentially homogeneous.

The relationship between technologies in emergency logistics technology system is relatively simple. Compared with other elements, there are many elements in emergency logistics system, including the relationship among various elements, including tasks, activities, capabilities and equipment. According to the relationship between the demand and the demand of technology and equipment, can roughly determine the degree of close coupling between the technology: technology and technology combination of the same or similar equipment or capacity requirements and demand traction in is very close, and the relationship between the different combination technology is very loose.

The structure of the emergency logistics technology system has a hierarchical structure. This is determined by the characteristics of the capacity demand and equipment demand at the source. The demand for capabilities and equipment needs hierarchical structure. The clearer the capabilities and equipment needs, the clearer the technology, the more technology level; on the contrary, the vaguer the ability demand, the more abstract technology is, and it can no longer continue to decompose.

The emergency logistics technology system has the attribute of the system level of emergence, evolution and so on. The characteristics of technology emerge as the characteristics of the technical system, but the characteristics of the technical system level can only be understood and studied from the system level. The technology is constantly changing. This is reflected in the evolution of technology system, changes in technology in two aspects, one is the change of the technical attributes, such as the maturity of the technology, technical risk changes; two is the introduction of old technology and new technology brought out the change of structure of emergency logistics technology on the system.

The assessment of the emergency logistics technology system requires a large number of experts to participate in and consider a large number of subjective information. Because all the technologies in the emergency logistics system are abstract concepts, the attributes of the technology itself are mostly static. Therefore, the evaluation of emergency logistics technology system is based on expert knowledge, qualitative and quantitative methods. In addition, due to the extensive participation of experts, there is also a need to consider the uncertainty that may arise.

The status of the emergency logistics technology system is very important, and the demand is very urgent, but its related research is in a very immature stage. The structure of the emergency logistics system is the basis for the overall technical evaluation and optimization of emergency logistics, emergency planning is an important basis for decision-making of logistics system, is an important factor influencing the risk of emergency logistics system construction, is the guarantee to ensure the progress, cost and performance of the construction of the system. However, there are few institutions to carry out relevant research at home and abroad, but not many achievements can be used for reference, and it is still in the stage of exploration and empirical research. In comparison, the emergency logistics system has become one of the focus of research institutions and scholars at home and abroad, and has achieved important research results. Therefore, the relevant research results of the system and the emergency logistics system can serve the related research of the emergency logistics technology system.

Research Status

From the perspective of practical application, the existing emergency logistics technology system is difficult to meet the needs of the new situation. The national economic and social development has put forward new demands for the emergency logistics technology system. Meanwhile, the civil military integration strategy has also put forward new requirements for the emergency logistics 
technology system. However, the integration, innovation and matching of the existing emergency logistics technology system in China are insufficient.

From the perspective of theoretical research, there are still few research on the construction of emergency logistics technology system. The theories and methods of technology system in academic circles at present consider very few of the emergency logistics as an independent research content. The lack of relevant research results, relevant research contained in many related fields, and most of the emergency logistics system of emergency logistics system as a supplement and extension, no emergency logistics technology system is studied as a the whole object.

However, there are some ways to learn and learn about the construction of the emergency logistics technology system. There are few systematic research on the construction methods of technical system, and the closest concept to technology construction is technology prediction. Government organizations or enterprises in many countries have adopted technology prediction methods to obtain technology closely related to national defense and economic construction. The Japanese government attaches great importance to technology forecasting. Since 1971, the Japanese Ministry of science and technology has organized a nationwide technical forecast survey every 5 years. After years of continuous development and improvement, technology-forecasting survey has become a relatively mature, standardized and worthy of the basic research work in Japan. The first technology prediction in Germany was carried out jointly with Japan in 1992. The second survey was completed in 1998. Over 2000 experts from enterprises, management, universities and research institutions participated in the survey, involving 12 technologies and 1000 technologies. China also attaches great importance to technology prediction. The Ministry of science and technology of national technology roadmap in scientific research review of national economic and social development of science and technology development of the five strategic needs based on forward 30 strategic tasks need to focus on. On this basis, identified nine key technologies in the field of technology forecasting, design a list of alternative technologies. A prediction by pedigree; on each field 400 to 500 experts to carry out questionnaire and invite discussion, received a total of 794 candidate technology development as the focus of the next step.

Technology forecasting methods generally use Delphi Fa or large-scale questionnaire method, these methods have a lot of work force and financial cost of subjectivity, and the field of emergency logistics, technology pedigree generated may not satisfy the emergency logistics system service support capability requirement.

\section{Construction Method}

One of the characteristics of the emergency logistics technology system is that there are more subjective factors that rely on the construction of the emergency logistics technology system, that is, the participation of experts is more. Traction emergency logistics technology system is not a single capacity demand and equipment demand. In addition, the technologies that constitute the emergency logistics technology system need to reflect the requirements of comprehensiveness, integrity and foresight.

\subsection{Construction Method of Traditional Emergency Logistics Technology System}

The existing emergency logistics technology system is displayed and built in the form of technical list, and all of these technologies are drawn from the equipment needs. The basic principle is to first obtain equipment requirements, and equipment requirements in accordance with the functional modules are decomposed into the component level, that is to get the corresponding technologies, the same equipment demand the technology is in the same group in support; the relationship between the technologies not reflected in the technology list. The methods used are many rounds of discussions between experts. This technology list can also meet the needs of equipment, and is forward-looking. Combined with expert experience, it has practical significance and can cover emergency logistics technology architecture.

However, there are three shortcomings in this approach: 
(1) It is difficult to ensure that technical redundancy does not appear in the list of technology obtained. Common techniques for supporting equipment (possibly component level) implementation will appear in a number of technical groups, which will create redundancy.

(2) Ignoring the relationship between technologies, the relationship between technologies is an important part of the emergency logistics technology system structure and subsequent satisfaction analysis, but it is difficult to be reflected in the list of technology.

(3) The completeness of the list of technology cannot be guaranteed. This method is likely to omit some common technologies, such as the inter - platform, between the equipment and the equipment.

\subsection{Construction Method of Emergency Logistics Technology System Based on the Principle of System Engineering}

The relationship of various technologies in the emergency logistics technology system is also obtained from the traction of capacity demand and equipment demand. Starting from three types of technologies, including special technology, shared technology and strategic technology, the following four steps are given to construct the hierarchical structure of emergency logistics technology system.

The first step, from capacity demand to equipment demand, to obtain specific equipment support technology to specific emergency logistics equipment. As the upper level of capability requirements and equipment requirements have hierarchical properties, the technology obtained by this step also has a hierarchical attribute. At this time, the emergency logistics technology system is the list of traditional tree structure technology, but because of the hierarchy attribute of capability demand, it is more hierarchical.

The second step is to integrate the technology of emergency logistics equipment sharing and the technology of cross platform emergency logistics equipment sharing based on the original technology list. For the former, this step can eliminate redundancy in the technical list, and for the latter, the purpose of this step is to make up for its shortcomings. Both are the common technology of emergency logistics equipment, but the way of obtaining is different.

The third step, to increase the demand for the future emergency logistics support, the abstract, summary of the capacity demand traction of emergency logistics strategic technology. The introduction of emergency logistics strategy technology into the emergency logistics technology system is an important supplement and perfection to the last step of the emergency logistics technology system.

The fourth step, based on the above three steps, summarizes the special technology, the common technology and the strategic technology, and constructs the emergency logistics technology system.

In short, based on the emergency logistics technology list, mainly for the three improvements: one is merged with shared technology between different kinds of emergency logistics equipment; two is to increase the share of emergency logistics equipment technology cross platform, the three is to increase the strategic frontier technology dynamic. Through these three improvements, the emergency logistics technology system can not only meet the needs and equipment needs of the current emergency logistics system construction, but also guarantee the strategic needs of emergency logistics in the coming period. In the emergency logistics technology system, most of the special technologies of emergency logistics equipment occupy the majority regardless of quantity and category. The special technology of emergency logistics equipment is the main source of emergency logistics technology system, and sharing technology and strategy technology is an important supplement. The hierarchy of technology is determined by the clarity of capacity requirements. The clearer the capabilities demand, the clearer the equipment demand, the clearer the technology, the more technology level. The hierarchical structure of equipment and technology with multi (up to three), according to the common technology of emergency logistics equipment technology acquisition has the same level; due to adapt to multiple emergency logistics equipment platform requirements, common technology platform, the level is relatively less; for slightly more abstract technology, generally cannot be further decomposed. 


\section{Construction Principle and Guiding Ideology}

\subsection{The Guiding Ideology of Constructing the Emergency Logistics Technology System}

The construction of emergency logistics system, with Deng Xiaoping theory and the important thought of "Three Represents", Scientific Outlook on Development and the Central Military Commission, the new period strategy as a guide, grasp the overall layout of the implementation of the development of tourism. the concept of innovation, harmony, green, open, sharing, on the basis of the "People's Republic of China emergency response law" and all kinds of emergency plans and other relevant laws and regulations, its goal is to enhance the government and military to respond to natural disasters and other emergencies and diversified military emergency support capabilities. Based on the combined development of military logistics and local logistics, breaking the original segmentation situation, based on overall national strength, based on the core competence, give full play to the overall advantages the combination of military and civilian.

The construction of emergency logistics system, should grasp the depth of the emergency logistics benefit mechanism, the integration of resources, and combined with the flat urgent civil military integration, scientific management, intelligent scheduling, full control, rapid operation, accurate delivery "as the main line, to solve the bottleneck problem of large-scale integration of emergency supplies scheduling, rapid transit and accurate delivery of key links the key technology research. To provide technical support for the construction of China's "efficient, fast and precise" emergency logistics support system, we will lead a high-level national emergency logistics system construction and industrial development.

\subsection{The Basic Principles of Constructing the Emergency Logistics Technology System}

The construction of emergency logistics system, in accordance with the needs, rational planning, demand traction, both benefits, based on the present, focus on the future, supporting system, and steadily push forward the development of military and civilian. Organic fusion principle, establishes a set to achieve a short time, low cost, high precision, high flow, high flexible emergency logistics technology system, improve the modernization level of emergency logistics in our country as a whole.

Peacetime, reasonable co-ordination. The emergency logistics technology system should take into account the period of peace and war. The emergency logistics technology system should be better achieved in the peacetime period, mainly based on local governments, organizing and directing in accordance with the unified administration area, coordinating the deployment of personnel, equipment and supplies, and giving full play to the main role of the army in disaster relief. During the war, the central command was unified. The logistics departments worked together, relying on the folk logistics resources, to integrate the local mature logistics infrastructure, logistics tools, logistics technology and military logistics demand, and applied them to the field material support. In the peacetime integrated emergency logistics construction, we should strengthen the combat readiness at all times and improve the peacetime transformation and construction to the wartime.

Demand traction and benefit. As technology comes from demand, what kind of capacity needs needs to be developed to match the technology. The emergency logistics technology system is generally displayed and built in the form of a technical list, and various technologies are drawn from the capacity requirements. Generally speaking, emergency logistics technology includes emergency logistics hard technology and emergency logistics soft technology. At the same time, we should also take into account the benefits. Under the premise of meeting the needs of technology, we should try to develop technological system at a low cost and avoid unnecessary waste, while meeting the usual emergency and wartime needs, and at the same time, we should maximize the economic benefits.

Foothold now, look at the future. The purpose of the construction of the emergency logistics technology system is to meet the requirements of the current and future emergency logistics systems. A complete evaluation of the construction of emergency logistics system and the rationality of the standard is to meet the capacity requirements. At the same time, here including current and future capacity requirements; should be based on the existing technology as the foundation, in time (distance and velocity), cost (energy), precision (flow), flow, flexible (process), reliability (risk) put 
forward higher requirements and so on. Alternatively, by improving the technology property of the upgrading and development of technology to promote the construction of the system.

System matching, steady advance. The construction of emergency logistics technology system should be of proper level, clear responsibility, complete elements, balance of strength, complete function and complete structure. The technology system is made up of many independent sub technologies, and different sub systems are formed. To build these independent sub technologies, there must be some related supporting constructions.

Military and civilian integration, organic integration. In the light of the formulation of national, local and military logistics planning, the policy of "military and civilian integration" is carefully carried out. We should make clear the direction of development, the development goal, the focus of development, the mode of development, the steps of implementation and the main measures taken, and make a good job of macro decision making. The principle of system science is used to organize and coordinate human, material and financial resources. We should strive to maximize the overall efficiency, to achieve emergency logistics facilities and equipment integration, emergency logistics information fusion, emergency logistics technology integration, emergency logistics theory integration, logistics technology standards integration and emergency logistics evaluation system integration.

\section{Analysis on the Capacity Requirement of Emergency Logistics}

In this paper, the construction of emergency logistics system is based on the principle of system engineering, using the method of analysis ability based on the requirements in accordance with the framework of "active ability technology", in demand analysis based on the construction of emergency logistics, emergency logistics system.

\subsection{Analysis of the Composition of Emergency Logistics Activities}

Through the whole process of emergency logistics activity analysis, emergency logistics activities can be obtained generally include: emergency needs emergency supplies ready before emergency logistics, equipment preparation, human resources and social mobilization preparation and emergency rescue activities in the process of analysis and confirmation. Emergency supplies and procurement, transportation, storage and handling, packaging, distribution processing, distribution, recycling and other activities of emergency supplies. According to the nature of the activity, each activity includes activity-based activities and managerial activities.

\subsection{List Emergency Logistics Capacity List}

According to the target requirements of emergency logistics activities, each activity needs the corresponding ability to complete the corresponding task. The target requirements include time (distance, velocity), cost (energy consumption), accuracy (flow direction), flow rate, flexibility (process), reliability (risk), etc. 
Table 1. Emergency Logistics Capacity List

Activity name

$\begin{array}{cc}\text { Fund preparation } & \text { The scientific and rational development of emergency } \\ \text { budget }\end{array}$

\begin{tabular}{ccc}
\hline Storage & $\begin{array}{c}\text { Optimize the layout and design of emergency logistics } \\
\text { node, scientific management of emergency supplies }\end{array}$ & $\begin{array}{c}\text { Short time, low cost, high } \\
\text { precision, large flow, strong } \\
\text { flexibility }\end{array}$ \\
\hline Handling and handling & Reasonable and efficient handling of emergency \\
supplies & $\begin{array}{c}\text { Short time, low cost, high } \\
\text { precision, large flow, strong } \\
\text { flexibility }\end{array}$ \\
\hline Packing & Reasonable and efficient packaging of emergency \\
supplies & $\begin{array}{c}\text { Short time, low cost, high } \\
\text { precision, large flow, strong } \\
\text { flexibility }\end{array}$ \\
\hline Circulation processing & Reasonable and efficient processing of emergency & $\begin{array}{c}\text { Short time, low cost, high } \\
\text { precision, large flow, strong } \\
\text { flexibility }\end{array}$ \\
\hline
\end{tabular}

Target requirements

Low cost

Short time, low cost, high

precision

Low cost and high precision

low cost

low cost

Short time, high precision

Short time, high precision

Short time, low cost, high

precision, large flow, strong flexibility

Short time, low cost, high (rong

Short time, low cost, high flexibility , large flow, strong large flow, strong flexibility

\section{Establishment of Emergency Logistics Technology System}

Push to accelerate the development of emergency logistics technology, should adhere to the integration of innovation, give full play to the advantages of the characteristics of the integrated system of modern logistics have, to effectively integrate and utilize existing logistics technology. Explore the realization from focusing on the elements of construction to focus on system construction, the construction of emergency logistics system supporting the system, reasonable structure, provide a solid material foundation and reliable technical support for improving the operation efficiency of emergency logistics.

Based on the principle of system engineering and the demand analysis method based on capability, this paper constructs the emergency logistics technology system from the emergency logistics process, which refers to the procedures of the basic logistics and logistics activities in the whole process of emergency logistics. These basic abilities are effectively combined and joined together, which will become the overall function of the logistics, and can realize the general purpose of the logistics system reasonably and effectively. General logistics flow generally starting from the preparation stage, including material packaging, handling, transportation, material delivery to the end, including logistics information processing technology, and logistics processes in general, in the process of emergency logistics to establish emergency logistics system, this paper joined the acquisition technology demand emergency logistics forecasting and emergency resources, see table 2. 
Table 2. Emergency logistics technology system

\begin{tabular}{|c|c|c|}
\hline & & Reserve Prediction Technology \\
\hline & Emergency logistics demand forecasting tecnnology & Fast response requirement assessment technology \\
\hline & & Emergency resource purchasing technology \\
\hline & & Emergency resource raising technology \\
\hline & & Reserve strategy layout technology \\
\hline & & Facility location technology under uncertain conditions \\
\hline & Emergency logistics preparation technology & Joint Reserve Technology for emergency materials \\
\hline & & Emergency material reserve rotation technology \\
\hline & & High efficiency automatic emergency storage technology \\
\hline & & Moisture proof packaging technology \\
\hline & & Shock absorption packaging technology \\
\hline & 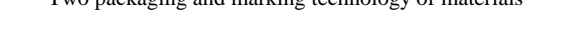 & Packaging technology of drug materials in temperature control \\
\hline & & Fast identification and identification technology \\
\hline & & Loading and strengthening technology of cargo \\
\hline & & High load and heavy lifting lifting and lifting technology \\
\hline & High efficient handling and handling technology & Mobile high speed transportation technology \\
\hline Emergency & & High speed cross-country handling technology \\
\hline technology & & Rapid assembly binding technology \\
\hline & & Path planning technology under the uncertainty of dynamic demand and road condition \\
\hline & & Multimodal transport technology for emergency materials under uncertain conditions \\
\hline & & Rapid pass through technology of emergency logistics node \\
\hline & & Heavy haul highway transportation technology \\
\hline & 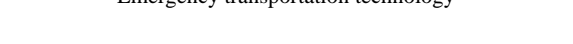 & Cross-country road transportation technology and technology \\
\hline & & Aircraft landing technology under complex terrain and climate \\
\hline & & Takeoff technology of aircraft in plateau area \\
\hline & & Air transportation technology for heavy materials and equipment \\
\hline & & Location technology of allocation center based on large data \\
\hline & & Quick setting technology for temporary allocation center \\
\hline & Fast and accurate delivery technology of the end dialing point & Emergency resource scheduling technology considering timeliness and dynamics \\
\hline & & Fast and accurate delivery technique at the end of adverse climate and geographic conditions \\
\hline & & Precision aerial delivery technology based on large data \\
\hline & & Reverse emergency logistics technology \\
\hline & Other Technologies & Evaluation technology of emergency logistics capability \\
\hline & & Whole course safety monitoring and control technology for emergency logistics of dangerous goods \\
\hline
\end{tabular}

\section{Summary and Prospect}

The research and development of emergency logistics technology in China is still in its infancy, and there are few theoretical research results and successful cases, which can be used for reference. The emergency logistics standard is equipped with less technical equipment, and the application of $\mathrm{R}$ \& D is lagging behind. The development and application of emergency logistics technology project is facing certain difficulty. Besides, China's emergency logistics technology covers a wide range of fields, involving many government business departments, and the R \& D Application of emergency logistics technology projects need to be recognized by governments, enterprises and other related aspects, and the implementation of specific organizations is very difficult. Therefore, the 
development and application of emergency logistics technology project is an arduous and challenging thing.

At the same time, what kind of route is the development of emergency logistics technology is an important basic issue of R \& D Application of emergency logistics technology, and the core link of the construction of emergency logistics technology system. Technology development path is correct, technology development, development of the world is getting broad prospects. The path of technology development is not right, and the application of technology research and development will enter a dead end.

Although the world advanced technology, but the sudden natural disasters and public health incidents such as "natural", making mistakes, terrorism, regional military conflicts such as "man-made" still occur, these events are difficult to predict and forecast some, some even can forecast, but due to the forecast time and the occurrence of time lag is too short to deal with materials, personnel, funding is difficult to achieve the effect of time and space effect, so we need to improve the measures. For our country, the emergency logistics is still a new thing, compared with the developed countries, China is still in the initial stage, and the development is relatively lagging. Moreover, China is a country with high natural disasters. There are many urgent needs for improvement in emergency logistics technology. It is urgent to improve the development policy of emergency logistics technology.

\section{Acknowledgments}

This work is supported by the National Key Research and Development Program of China(grant 2016YFC0803201).

Corresponding to zhanglei@lsec.cc.ac.cn.

\section{References}

[1]. Chen Hui. Main Problems and Suggestions on Emergency Logistics System in China [J]. China's Circulation Economy, 2014, 28 (08): 20-24.

[2]. Shu Mian. Construction of emergency logistics system under the condition of information technology [J]. Logistics Science and Technology, 2013, 36 (08): 116-118.

[3]. Huang Dingzheng. Analysis of emergency logistics technology system based on activity theory [J]. Logistics Technology, 2013, 32 (07): 269-272.

[4]. Sun Huarui, Wang Xunqing, Xue Yaofeng. Research Status and Development Trends of Emergency Logistics [J]. Chinese Journal of Safety Science, 2010, 20 (10): 165-170.

[5]. Wang Zongxi. On the construction of emergency logistics several issues [J]. China's Circulation Economy, 2009, 23 (03): 20-22.

[6]. Xu Dong, Huang Dingzheng on the emergency logistics system of several considerations [J]. China Ocean Shipping, 2008 (09): 39-41 +12.

[7]. Wang Zongxi. Vigorously promote China's emergency logistics construction and development [J] China Logistics and Purchasing, 2007 (24): 37-39.

[8]. XIE Ruhe, QIU Zhu-Qiang. Establishment and Operation Management of Emergency Logistics System [J]. Logistics Technology, 2005 (10): 78-80. 